Orbis Tertius, vol. XXIV, n 29, e108, mayo-octubre 2019. ISSN 1851-7811

Universidad Nacional de La Plata

Facultad de Humanidades y Ciencias de la Educación

Centro de Estudios de Teoría y Crítica Literaria

\title{
El personaje traductor y las disputas por el control de la palabra, en "Las dos orillas", de Carlos Fuentes
}

The translator as a character and the disputes over speech control in Las dos orillas, by Carlos Fuentes

María de Lourdes Ortiz Sánchez

Universidad Autónoma de Zacatecas,

México orsalm@hotmail.com

\section{Resumen:}

En el universo narrativo que plantea Carlos Fuentes, en Las dos orillas, un elemento de importancia es la lengua, en tanto medio de comunicación e instrumento de dominio, es utilizada por los personajes protagonistas, Jerónimo de Aguilar y Malinche, con intereses particulares para obtener beneficios. Ambos son conscientes que el conocimiento de la lengua, hispana e indigena, representa un arma que bien utilizada les confiere poder, por lo cual suscita la pugna, no sólo entre ellos sino entre dos culturas, la americana y la española; una sometida mediante las armas, los caballos y la palabra de connotación religiosa, la otra se impone como soberana que domina durante trescientos años.

Palabras Clave: Conquista, Lengua, Poder, Carlos Fuentes.

\section{Abstract:}

An important element in the narrative universe proposed by Carlos Fuentes in Las dos orillas is the way language is used as a means of communication and as an instrument of domination. The protagonists, Jerónimo de Aguilar and Malinche, use language for their own interests and personal gain. Both are aware that knowledge of Spanish and indigenous languages is a valuable weapon which grants them power. This causes conflict between them and between the Spanish and American cultures: the latter, subjected by guns, horses and religious language; the former, imposing its sovereign dominion for three hundred years.

KEYWORDS: Conquest, Language, Power, Carlos Fuentes.

\section{LAS DISPUTAS ENTRE INDÍGENAS Y ESPAÑOLES}

Las fuentes de conocimiento del mundo prehispánico, así como las crónicas escritas durante la conquista, la Crónica Mexicáyotl y la Historia general de las cosas de la Nueva España, revelan que las civilizaciones mesoamericanas vivían en constante pugna por el territorio y el poder, es decir, había la necesidad de expandir los dominios y obtener beneficios económicos y políticos. En los aztecas se ha identificado una mística guerrera impulsada por Tlacaélel -el poder tras el trono y consejero de los monarcas-, por lo cual en relativamente poco tiempo dejaron de ser el pueblo cuyo rostro nadie conocía, para forjar un pasado ilustre y glorioso como descendientes de los toltecas. Es así que, según sus mitos, estaban llamados a la grandeza y su dios Huitzilopochtli -colibrí de la izquierda- les había trazado el camino para ser señores; de esta manera, legitimaron su pasado y se consolidaron como el pueblo del sol, que tenía una misión de importancia en la vida (León-Portilla, 2003). Los aztecas como pueblo hegemónico tenían enemigos que buscaban su caída, de ahí que cuando los de Tlaxcala y Cempoala se enteraron de la llegada de los españoles, ${ }^{1}$ vieron la oportunidad de cumplir sus anhelos de liberarse del yugo, sin vislumbrar que ellos también perecerían o compartirían la situación de servidumbre con los sobrevivientes de la conquista de Tenochtitlán.

En las crónicas escritas por autores hispanos también se perciben las pugnas por el poder, la necesidad de protagonismo, de informar con apego a intereses particulares (Cortés, 1998), aunque hubiese quienes expresaran absoluto apego a la verdad y dieran un supuesto testimonio de los hechos ocurridos. No obstante, las crónicas representan la evidencia histórica de una época, creadas por necesidad o por obligación, esto es, para dar cuenta al monarca español de los recursos humanos y materiales encontrados. Entre los cronistas 
destacan sujetos con cierta formación, como Hernán Cortés, quien realizó estudios en la Universidad de Salamanca, una de las más modernas de la época. Asimismo, se identifican versiones de la conquista en autores laicos y clérigos, de estilo diverso, intenciones veladas o evidentes, con afán de destacar como protagonistas de la empresa de conquista y colonización, como las de Bernal Díaz, Juan de Torquemada, Garcilaso de la Vega "el Inca", Toribio de Benavente "Motolinía”, Francisco López de Gómara, Bernardino de Sahagún, Bartolomé de las Casas, José de Acosta, entre otros, quienes recogieron la diversidad de visiones sobre un hecho histórico sin precedente para América y Europa (Masia, 1971).

En la versión histórica de Bernal Díaz del Castillo hay el afán de hablar con apego a la verdad, porque participó en las tres expediciones, la de Francisco Hernández de Córdoba, la de Juan de Grijalva y la de Hernán Cortés; por tanto, tenía una visión amplia de los hechos. Una vez terminada la conquista poseía lo que muchos aspiraban en su época: la gloria, por lo cual se adjudicó el mérito de ser "[...] uno de los primeros descubridores y conquistadores de la Nueva España y sus provincias y Cabo de Honduras y de cuanto hay en esta tierra [...]" (2002, p. 15). No obstante, se mostró resentido por su poco caudal pese a contar con encomienda de indios en varios pueblos. Empuñó la pluma en nombre de los anónimos partícipes que no dieron su testimonio de la conquista. En las páginas de su historia se recoge la intención de hablar de lo ocurrido, confiado en su memoria, en lo que captó con sus sentidos, para refutar a los que se atribuyeron todos los méritos, es decir,

[...] en respuesta de lo que han dicho y escrito personas que no lo alcanzaron a saber ni lo vieron [...] salvo hablar al sabor de su paladar, por oscurecer nuestros muchos y notables servicios, porque no haya fama de ellos ni sean tenidos en tanta estima como son dignos de tener [...] (Díaz, 2002, p. 16)

Bernal Díaz evidencia las disputas entre los españoles, pero también es uno de los que critica las rivalidades y la división entre los nativos.

La conquista militar y espiritual, por su parte, suscitó discusiones, pugnas y polémicas de todo tipo, políticas, filosóficas, teológicas y jurídicas, como la que sostuvieron Bartolomé de las Casas y Juan Ginés de Sepúlveda; el primero a favor de la libertad de creencias, para él la predicación se impartiría no por la fuerza sino acudiendo a la persuasión, además, aceptó el nivel de civilización y cultura de los indios, discutió su grado de racionalidad, rechazó que los pecados de los indios fueran justo título para hacerles la guerra. Sepúlveda, a su vez, defendió la conversión por la fuerza, consideró lícito a la cristiandad pelear contra los infieles, acudió a las ideas aristotélicas para justificar la dominación. ${ }^{2}$ Argumentó que la guerra no era para depredar ni ejercer crueldad, sino para pacificar e imponer el orden, por lo cual consideró que la predicación del evangelio, en tanto misión de la Iglesia, no se podía impedir. Consideró a los indios siervos por naturaleza, bárbaros, idólatras, sin inteligencia, y que era necesario apartarlos de la antropofagia y la sodomía. Recomendó utilizar la fuerza física para someterlos y que aceptaran el evangelio.

El dominio político y económico propició la implantación de las instituciones y costumbres hispanas. Los indios fueron segregados de su hábitat, sometidos mediante la pólvora, los caballos y la palabra cargada de connotaciones religiosas; por lo cual se afirma que la conquista definitiva fue la de carácter espiritual, porque significó quitar desde la raíz las prácticas politeístas, que tal vez es debatible porque también los investigadores señalan el sincretismo o mestizaje cultural. Desde la llegada de los primeros conquistadores y misioneros se dio un proceso de apropiación de lo americano mediante la lengua, la exploración o reconocimiento. Es así que "La conquista expulsó al indígena del escenario histórico e instauró un discurso nuevo en casi todos los aspectos. El conquistador impuso un nuevo lenguaje e introdujo una nueva manera de representar el pasado" (Florescano, 2002, p. 256). La lengua hispana se mestizó porque fue el vehículo de expresión del descubrimiento, exploración y conquista del Nuevo Mundo. Los españoles utilizaron significantes de su lengua para nombrar los lugares, la flora, la fauna, los hombres y las culturas nativas; por desconocimiento o por apropiarse de todo lo conocido, lo americano cedió ante las designaciones del español y perdió su identidad indígena. 
El conquistador impuso su lengua al transcurrir del tiempo, pero también destruyó templos, palacios y ciudades para erigir los propios de acuerdo a su cultura; estableció un régimen conforme a los parámetros europeos, por lo cual "[...] la fisonomía del territorio, las rutas que lo cruzaban y su relación con el mundo exterior fueron definidos por la geografía y los intereses del conquistador” (Florescano, 2002, p. 257). En varios casos la toponimia cedió ante la lengua hispana, otras veces se mestizó, una más se conservó, en la flora y en la fauna se dio un proceso de encuentro, descripción y comparación. Hubo quien, incluso, vio en su tratamiento un tema novedoso, que le daría fama y prestigio, y acertó porque en la distancia de varios siglos se observa como un tema renacentista, que cobraría especial importancia en la Hispanoamérica del siglo XIX. El autor aludido es Gonzalo Fernández de Oviedo, creador de Sumario de la natural historia de las Indias y de Historia general y natural de las Indias. Las crónicas que trataron el tópico de la naturaleza mostraron el asombro e interés por conocer las novedades americanas, pero además las diferencias sobre las europeas. Conocer el vasto y diverso Nuevo Mundo tiene varias implicaciones, por un lado, revelar las riquezas obtenidas mediante la conquista, presumir el poderío español, por el otro, "Nombrar, describir y clasificar el mundo físico americano significa apropiárselo" (Florescano, 2002, p. 258).

En el cuento "Las dos orillas", de Carlos Fuentes, la historia se ubica en el siglo XVI, durante los primeros encuentros entre españoles e indios; en el universo ficcional se destaca la importancia de la lengua, pues mediante su uso el conquistador se apropia del espacio descubierto, asimismo, se enfatiza la función de los traductores Jerónimo de Aguilar y Malinche o Marina, ambos personajes históricos. Uno es el náufrago español que aprendió la lengua maya en Yucatán, y la otra es una india que dominaba el náhuatl y el maya, quien de niña fue vendida como esclava. Ambos fungen como traductores e intérpretes en la empresa de exploración y conquista de Hernán Cortés. El conflicto entre ellos se suscita por la disputa y el control de la palabra, ya que traducen de acuerdo a sus intereses, engañan cuando les conviene y alteran los mensajes si se requiere.

El objetivo en el presente artíoculo es analizar el perfil psicológico de los personajes, que los revela como tendenciosos, mentirosos, manipuladores de los mensajes, controladores del discurso e inventores de sueños, lo cual trae como consecuencia una pugna por el poder. La metodología consiste, en el primer apartado, en dar un panorama general de los conflictos que existían entre las civilizaciones indígenas antes y durante los enfrentamientos con los españoles, lo cual propició que establecieran alianzas y lucharan en favor de la causa hispana, contribuyendo así con la derrota de los otros y la propia. Los españoles, por su parte, también revelaron diferencias en sus intereses económicos y políticos, por lo cual puede afirmarse que no fueron un grupo homogéneo. Se incluye, asimismo, una reflexión sobre el lenguaje y cómo este se utilizó durante la conquista espiritual para persuadir a los naturales de aceptar la conversión al cristianismo. En la última parte se analizan ambos personajes en su hacer y en su decir, y cómo se enfrentan con el arma que conocen y dominan: la lengua. El tipo de lectura que se sigue es la dirigida, que consiste en respetar el orden de la escritura, es decir, considera cada línea y párrafo de manera minuciosa: "[...] puede partir de una teoría específica acerca del cuento (o la narrativa) en general o de una teoría acerca del subgénero del cuento al que pertenece [...]" (Zavala, 2007, p. 13).

\section{EL LENGUAJE Y SU IMPORTANCIA}

La palabra, sin duda, tiene una multiplicidad de funciones, desde preservar la memoria de una comunidad para transmitir historias, relatos ficticios, sentimientos. La vida está impregnada de palabras, incluso, por lo general, se emplean sin meditar en su complejidad sintáctica, semántica, fonética, en las reglas gramaticales, ni en la polifonía. La capacidad de hablar distingue al hombre respecto de los animales. Hablar es, en ese sentido, connatural, y no nace de un acto de voluntad. Conesa y Nubiola aseguran que “[...] es el propio lenguaje lo que hace al hombre capaz de ser el ser vivo que es en tanto que hombre. El hombre es hombre en cuanto que es capaz de hablar" (2002, p. 17). Se trata de un hecho que lo distingue y 
es propio de él. Heidegger afirma que la palabra puesta en diálogo es un bien del hombre y es el más peligroso de los bienes; con ella puede ser dicho lo más puro, lo oculto, lo confuso y lo vulgar, es decir, el Ser del hombre se funda en la palabra; con ella testimonia su pertenencia a la tierra, su propia realidad, porque donde está la palabra hay mundo (Heidegger, 1992).

Los seres humanos tienen la capacidad de hablar precisamente por el logos, se trata de entes que hablan por la inteligencia. Conesa y Nubiola aclaran que "Gracias al lenguaje, la religión y la ciencia los seres humanos han construido su propio universo, un universo simbólico, que les posibilita entender e interpretar, articular y organizar, sintetizar y universalizar su experiencia” (2002, p. 24). El lenguaje es una actividad que surge por la necesidad de comunicación, esto es, se trata de algo tan natural como caminar o respirar. Una actividad que impregna toda la vida. Entre el lenguaje y la cultura ${ }^{3}$ hay una relación dialéctica, pues se trata de un producto cultural que la refleja, pero también es condición de la cultura y contribuye a crearla, es decir, "La cultura es condición del lenguaje, pero el lenguaje es también condición de la cultura” (2002, p. 25). El lenguaje también es creación, es arte, realizado por un espíritu libre. Interviene de manera decisiva en el conocimiento y apropiación de la realidad. El ser humano objetiva el mundo a través del lenguaje, lo utiliza para fundar la comunidad en la que se basa la cultura.

Lo anterior puede relacionarse con el hecho histórico del descubrimiento y exploración del continente, que trajo como consecuencia el sometimiento de los diversos grupos indígenas no sólo mediante las armas, sino a través del uso de la palabra, misma que utilizaron los frailes para lograr la conversión de los naturales, para que vivieran de acuerdo a los mandamientos de la ley de Dios y pasaran a formar parte de la comunidad católica. Utilizaron los significantes para expresar sermones, discursos, o bien la palabra puesta en diálogo en las obras de teatro, pero siempre trataron de construir un discurso contundente. La palabra también la utilizaron los exploradores para designar el mundo recién descubierto, para inventariar las riquezas y de esta manera incorporar el universo que se desvelaba, al ya conocido por ellos (Ricard, 2005). Es mediante la palabra que confrontan y subliman el mundo conocido con el que se descubre ante sus ojos, por ejemplo, en México en 1554, de Cervantes de Salazar. También a través de la palabra en verso exaltan la belleza de la ciudad y la obra hispana, como ocurre en La grandeza mexicana, de Bernardo de Balbuena, quien utiliza los recursos de la hipérbole, el epíteto y la metáfora para embellecer la obra hispana.

\section{LA LENGUA COMO INSTRUMento DE PODER EN LOS PERSONAJES MALINCHE Y Jerónimo DE AgUiLAR}

La narrativa se consolida como género en el siglo XIX, surge la llamada novela de folletín o por entregas, en la cual se plantean ciertos conflictos de clase social, presenta una marcada inclinación didáctica y moralizante, y se utiliza el recurso de la hipotiposis con el fin de ambientar los cuadros de costumbres. El maniqueísmo es un elemento que caracteriza a los personajes, los buenos y los malos, víctimas y victimarios, viven la desgracia y la fortuna, la felicidad y el sufrimiento. En la centuria subsecuente, Redondo Goicoechea afirma que "La historia de la novela en el siglo XX ha sido la historia de esta lucha por el poder de la palabra, en el nivel discursivo, que es donde fundamentalmente se expresa la ideología de un relato, entre narradores y personajes" (1995, p. 32).

En el universo literario los personajes y sus acciones cobran particular importancia. El personaje se define como un efecto de sentido, de tipo moral y psicológico, logrado mediante determinadas estrategias de carácter discursivo. El nombre es de suma importancia y permite no sólo su identificación, sino que configura una identidad (Pimentel, 2005). En "Las dos orillas" ${ }^{4}$ los protagonistas y antagónicos son Malinche y Jerónimo de Aguilar. La mujer fue bautizada como Marina, en lengua indígena Malinalli o Malintzin, el nombre es de origen latino, variante de María, significa "la que procede del mar", se destaca por ser sociable, entregada, leal y sensual. De acuerdo al calendario náhuatl Malinalli alude al duodécimo signo, significa hierba, regeneración, cambio, entrelazamiento, mujer de conocimiento. Jerónimo proviene 
del griego hieros $=$ sagrado y onoma $=$ nombre, históricamente San Jerónimo se destacó como traductor de la biblia. El nombre implica la capacidad de comunicación, conlleva responsabilidad, tenacidad, apertura, ser emprendedor e independiente. Puede afirmarse, desde un enfoque de teoría literaria, que el nombre de un personaje es "[...] el principio de identidad que permite reconocerlo a través de todas sus transformaciones" (Pimentel, 2005, p. 63). Ambos protagonistas cumplen la función de colaboradores de Hernán Cortés durante los primeros encuentros con los indios. Se trata de los personajes que traducen los mensajes para lograr la comunicación entre dos culturas.

La teoría literaria destaca en los personajes no sólo su aspecto físico, sino su hacer y su decir, que se reflejan en sus ideas y en sus acciones; importan la calidad y la cantidad de la información que se tenga sobre ellos, las peculiaridades de sus discursos (Pimentel, 2005). En el cuento la historia está narrada en primera persona, es decir, se identifica un narrador autodiegético, que participa de forma directa en la diégesis, se asume como alguien confiable, porque vivió y participó en la empresa de descubrimiento y conquista. Los teóricos de la literatura señalan que una voz narrativa con estas características resulta poco confiable, porque domina su punto de vista sobre lo ocurrido y no permite conocer otros enfoques. Además, se debe considerar que la ideología de un texto no sólo se refiere a las alusiones de carácter social que se representan, sino en la manera en la cual se distribuye el poder de la palabra entre los narradores y los personajes (Asís, 1988). Por tanto, en los personajes interesa analizar el uso que hacen de la palabra, las funciones o el nivel discursivo que presentan.

El narrador es Jerónimo de Aguilar, quien relata desde un presente narrativo, pero utiliza el recurso temporal conocido como analepsis o retrospección temporal, que le permite insertarse en el pasado de la conquista de México, entre asechanzas y pugnas. Asegura: "Yo acabo de morir de bubas. Una muerte atroz, dolorosa, sin remedio. Un ramillete de plagas que me regalaron mis propios hermanos indígenas, a cambio de los males que los españoles les trajimos a ellos" (Fuentes, 2007, p. 10). Es un tipo de narrador con ciertas peculiaridades, ya que no sólo es consciente de su deceso, sino que también utiliza la prolepsis o avance temporal, pues afirma que su protagonismo histórico fue casi nulo, poco se dijo de él, y hasta ubica las veces que su nombre se menciona en la Historia verdadera de la conquista..., de Bernal Díaz del Castillo. Aguilar se constituye como:

Portador de una identidad escindida, hombre de las dos orillas porque vivió ocho años entre los mayas cuyos valores eligió, dotado en el momento de su narración de la omnisciencia y la infinita sabiduría que le otorga su condición de difunto [...] evoca con irónica melancolía las sempiternas caídas de los imperios y cuestiona [...] las posiciones de vencedores y vencidos de los enemigos al concluirse la Conquista (Olivier, 2007, p. 525)

Aguilar rememora la destrucción de templos, de ciudades, la mortandad entre los indígenas, las epidemias de viruela que también contribuyeron a disminuir de manera considerable la población nativa. Hace una reflexión acerca de las consecuencias del hecho histórico para ambos mundos, asume un papel heroico y sugiere que su manera de utilizar las palabras no fue sólo como instrumento, sino que él determinó con el contenido de sus mensajes el rumbo de la Conquista de México. El náufrago reflexiona así:

No nos engañemos; nadie salió ileso de estas empresas de descubrimiento y conquista, ni los vencidos, que vieron la destrucción de su mundo, ni los vencedores, que jamás alcanzaron la satisfacción total de sus ambiciones [...] Ambos debieron construir un nuevo mundo a partir de la derrota compartida (Fuentes, 2007, p. 11).

Reconoce que obtuvieron la riqueza con la esclavitud de un imperio poderoso, que al momento de enfrentarlos contaba con nueve veces el número de soldados españoles; no obstante, las alianzas indígenas, los caballos y la pólvora fueron decisivos. Los distintos testimonios históricos evidencian el uso que Cortés hizo de las palabras para prometer justicia, libertad y una vida mejor para los indios sometidos por los aztecas, a sus subalternos también les aseguró la equidad, la recompensa, la gloria y la riqueza. El Marqués del Valle, además, utilizó las palabras recargadas de hipérboles, metáforas e hipotiposis para congraciarse con el rey de España y adjudicarse el mérito de la Conquista de México, sin embargo, fue relegado por la Corona, mal reconocido y peor recompensado; nunca satisfizo su ambición de gloria y fortuna. En el universo ficcional el náufrago español denuncia la actitud alevosa de Cortés, su astucia para engañar y cómo mediante el discurso consiguió el poder y la gloria. 
En el universo narrativo se destaca el valor de Cuauhtémoc, último emperador azteca; Aguilar desde el encuentro de este con Cortés menciona su desempeñó como traductor, mediante el uso de la palabra adquiere poder, comunica las ideas, las tergiversa a su antojo; en ese proceso de traducción realmente ni Cortés ni Moctezuma se comunicaron, nunca conocieron el verdadero significado de sus palabras. Aguilar reconoce que inventó, traicionó y se burló de ambos, se revela en lo psicológico como un personaje alevoso, que modificó los mensajes para sacar provecho. En realidad, nunca prestó un servicio de manera desinteresada, asume las consecuencias de sus actos y afirma: "[...] me descubro ante la posteridad y la muerte como un falsario, un traidor a mi capitán Cortés que en vez de hacer un ofrecimiento de paz al príncipe caído, lo hizo de crueldad, de opresión continuada y sin piedad, y de vergüenza eterna para el vencido" (Fuentes, 2007, p. 16). Se justifica al decir que Cortés tampoco habló con la verdad, y cuando el cambió el significado de las palabras, en realidad descubrió sus verdaderas intenciones, en ese juego dialéctico de mentiras que revelan verdades y viceversa.

Jerónimo de Aguilar entra en pugna con la Malinche, quien también funge como segunda lengua del conquistador, se le identifica como la primera cristiana, quien traducía con soltura, pero también aconsejaba estrategias a Cortés, además, reveló la personalidad indígena, y traicionó a los de su raza cuando se volvió partidaria del hispano. Se trata de "[...] la mujer indígena que acarrea el dolor y el rencor de los desclasados pero también la esperanza, descubre a Cortés el secreto que comparten España y México, el odio entre hermanos (Méndez, 1999, p. 86). En ese sentido, se evidencia que la derrota de los pueblos indígenas también se debió a la traición de gente como la Malinche, quien confió las claves, que bien utilizadas trajeron como consecuencia la derrota y la esclavitud. Ella aconsejó aprovecharse de la división, la discordia, la envidia y las pugnas que existían en los diferentes pueblos. Malinche se muestra consciente del impacto y contundencia de las palabras, del poder que tiene al dominar la lengua del conquistador y la emplea con astucia y alevosía. Aguilar se asume pequeño en el disimulo, el engaño, la mentira y la astucia en comparación con ella y Cortés. Reconoce que ni Moctezuma fue capaz de usar la palabra en circunstancias adversas, porque cuando cayó prisionero no la utilizó con su pueblo. Aguilar actuó como intérprete y traidor con los españoles, pues expresó a Moctezuma que entre ellos existían los conflictos y desacuerdos y bien los podría utilizar para derrotarlos, sólo que este no hizo caso, incluso, pudo pactar una alianza con Pánfilo de Narváez y derrotar a Cortés. Moctezuma desaprovechó una oportunidad porque ya estaba derrotado desde el momento que los recibió en su palacio, asimismo, tenía la idea que el destino no podía alterarse y la derrota había sido anunciada con los presagios funestos. ${ }^{5}$

Aguilar en su tumba confiesa que sólo buscaba el triunfo de la raza indígena, como Malinche la victoria de los españoles, acepta que

Una mujer indígena [...] fue quien en realidad lo venció (al emperador azteca) desde su tierra, aunque con dos lenguas. Fue ella la que reveló a Cortés que el imperio azteca estaba dividido, los pueblos sujetos a Moctezuma lo odiaban, pero también se odiaban entre sí y los españoles podían pescar en el río revuelto [...] (Fuentes, 2007, p. 28).

El arma de ambos personajes, Malinche y Jerónimo, es la lengua, cada uno la utiliza de acuerdo a sus intereses, para aconsejar en el triunfo o en la derrota, a españoles o indios. Ella al principio sólo conocía el náhuatl y el maya; él tenía la ventaja que lo hacía superior porque su lengua materna era el español, sin embargo, Malinche pronto aprende la lengua de su amante y entra en pugna con Aguilar por el control de la palabra.

Jerónimo de Aguilar vive un drama cuando la Malinche lo desplaza como traductor de los españoles, le arranca el monopolio y domina la lengua hispana. Él, que un día se creyó el dueño de las palabras, sin embargo, un día toma conciencia de que la mujer se las arrebató. Aguilar se lamenta así: "[...] la lengua era más que la dignidad, era el poder; y más que el poder, era la vida misma que animaba mis propósitos, mi propia empresa de descubrimiento, único, sorprendente, irrepetible [...]" (Fuentes, 2007, p. 33). Acepta que la ventaja de la mujer radica en la cercanía con Cortés, y la astucia para arrancarle la lengua (metafóricamente) al conquistador durante los encuentros sexuales, ya que "Con la india aparece la voz femenina, no sólo la 
que habla las lenguas americanas y aprende el español, sino la que susurra al oído del amante las debilidades fratricidas" (Méndez, 1999, p. 86). A partir de ese momento, las pugnas son más evidentes en ambos personajes-traductores, se trata de una situación que propicia el enfrentamiento, la envidia, el conflicto por el poder y la manipulación de los mensajes de acuerdo a sus intereses. El narrador, en su rol de traductor, con frecuencia cambiaba el contenido del discurso, fingía a ambos interlocutores, porque ninguno se enteraba que invertía los significados, y trataba de quedar bien con ambos. Por ejemplo, a los sacerdotes indígenas advertía sobre las intenciones reales de los hispanos, de su propósito de someterlos, destruir sus dioses, y les advertía que no eran amigos sino enemigos que buscaban el exterminio de su imperio. En cambio, asegura: "Yo le dije a Cortés: No hay peligro. Están convencidos de que somos dioses y como tales nos honrarán” (Fuentes, 2007, p. 34). Malinche, por su parte, advertía a Cortés que tomara precaución ante las asechanzas de los indios, no confiara en ellos y que había peligro. Aguilar buscaba el fin del conquistador e intentaba evitar su llegada a Tenochtitlán, y que muriera en Cholula. Marina, en cambio, intrigó para que les hiciera la guerra a los indios, comunicó la existencia de una celada contra sus tropas, que tenían planes de sacrificarlos y consumir sus cuerpos.

En el universo narrativo se plantea que la mujer se impuso sobre el español, consiguió que los de Cholula murieran a manos de los invasores y se mostró enemiga de los de su raza. Al contrario de Aguilar, quien siempre aseguró estar con los indios y de forma constante los advertía de las palabras falsas de Cortés. Ambos reflejan un perfil psicológico que los evidencia como traidores de su raza, astutos y mentirosos. En el juego de la verdad de las mentiras, Aguilar traducía las palabras de bondad y paz del conquistador al vocabulario de la guerra para aguzar la ira indígena, en ese sentido, la posesión de la palabra convierte a los traductores en seres poderosos, que son capaces de decidir el destino de ambos Imperios.

Las pugnas por el poder se suceden entre ambos traductores, la contradicción en los significados, el uso de las palabras y su inversión. Los intérpretes son conscientes del poder que tienen para decidir la guerra o la paz; tener la lengua conlleva el dominio. En Jerónimo se conjuga el rencor, el odio y la envidia hacia Marina, primero porque en poco tiempo se ganó la confianza de Cortés y dominó la lengua española, segundo porque prefirió ser la concubina del líder de la tercera expedición, y con ello arruinó su sueño y el deseo, pues él reconoce que cuando la conoció: "Soñé toda la noche con su nombre, Marina, Malintzin, soñé con un hijo nuestro, soñé que juntos ella y yo, Marina y Jerónimo, dueños de las lenguas, seríamos también dueños de las tierras, pareja invencible porque entendíamos las dos voces de México [...]" (Fuentes, 2007, p. 39).

El retrato psicológico de la Malinche la revela como alguien con astucia e inteligencia no sólo para aprender la lengua del conquistador, sino para desplazar al colaborador, quien se convierte en oponente en esa lucha por el control de la palabra. Mientras Aguilar reconoce que debido al tiempo que convivió con los indios y la lejanía con la cultura hispana y su gente, él requirió reaprender la lengua, y en ese tránsito de auto reconocimiento, la Malinche se le adelantó. Marina utiliza sus cualidades femeninas para conquistar el cuerpo y la voluntad de su señor Cortés, le arranca la lengua y se la apropia sin que este dimensione el poder que ha adquirido la india. Los amantes se convierten en aliados y buscan la esclavitud de los nativos. Una se muestra superior frente a los de su raza, por compartir el lecho del conquistador y ser su lengua, sin saber que un día será abandonada, cargará con el fruto del mestizaje y será repudiada por los de su raza por considerarla traidora. En cambio, el otro pretende obtener todo el oro y la gloria que cree merecer.

El náufrago admite haberse unido a la tropa de Cortés por voluntad y siempre con la intención de convertirse en traductor del español al maya y viceversa. Al paso del tiempo y por las circunstancias, traiciona a los indios porque se enfila en las tropas invasoras, pero también a los hispanos porque advierte a los otros de sus mentiras e intenciones. Admite: "Me enamoré de mi nuevo pueblo, de su sencillez para tratar los asuntos de la vida [...] cuidaban su tierra, su aire, su agua preciosa y escasa, escondida en hondos pozos, pues esta llanura de Yucatán no tiene ríos visibles [...]” (Fuentes, 2007, p. 47). En él se evidencia la admiración por una cultura de la que cuando desembarcaron los españoles sólo quedaban los resabios y aun así suscitó asombro por sus construcciones, la traza de las ciudades, el calendario, la cerámica y las costumbres. En el relato, “[...] 
la ficción se ve evocada como el mejor avatar de la palabra. Más allá de la lengua, es la palabra que celebra Jerónimo de Aguilar en la perorata que cierra su relato" (Olivier, 2007, p. 527).

\section{Conclusión}

En el cuento "Las dos orillas" un elemento de importancia es la lengua, en tanto instrumento de comunicación y dominio de los otros, y de todo lo existente en el espacio descubierto. La lengua como clave del encuentro y el desencuentro entre culturas, como arma para dominar y desposeer a los vencidos. La lengua españolaodiciada por la india para usarla en beneficio de los invasores, en detrimento de los de su raza, como un medio para obtener privilegios y poder. La lengua como ingrediente de la disputa entre dos personajes, como pieza clave para lograr el triunfo o la derrota, la riqueza o la servidumbre. La lengua decidió el destino de un pueblo que surgió del norte, de un lugar paradisiaco llamado $A z t h$, peregrinó durante más de un siglo por el mandato de su dios Huitzilopochtli, llegó a la tierra prometida, superó las adversidades, enfrentó a sus enemigos y se consolidó como el pueblo del sol, pero no pudo evitar su destino, esto es, la caída presagiada a través de distintos signos.

Un mérito de Carlos Fuentes es explorar la historia de la Conquista de México desde la óptica de un personaje como Jerónimo de Aguilar, quien representa una entidad ficticia e histórica que plasma su visión de los acontecimientos desde su protagonismo histórico como traductor, desde esa identidad dual, como un ser bicultural y bilingüe. Aguilar se encuentra en las dos orillas y muestra su lado humano, sensible, emotivo al hacer el relato determinado por la perspectiva personal, subjetiva y hasta contradictoria. El autor recupera la técnica de los cronistas, la de Bernal Díaz del Castillo, para plasmar un enfoque político, utilizando la voz de un testigo de los hechos; en ese sentido, rescata su figura de difunto callado y le concede el status de cómplice de la embestida contra los indígenas. Jerónimo es el protagonista que conoció las dos orillas, es decir, la ibérica y la americana. Malinche, por su parte, representa a la mujer traidora, mentirosa, la barragana de Cortés, quien renegó de su pueblo y también se vio determinada por la dualidad cultural, que utiliza sus habilidades para aprender y dominar la lengua del conquistador y así aventajar a su oponente en esa lucha por el monopolio de la palabra. En el relato de Carlos Fuentes la figura del traductor cobra relevancia, ya que forma parte activa en ese proceso de descubrimiento y Conquista, incluso, en algún momento toma partido determinado por razones políticas o personales.

\section{REFERENCIAS}

Aristóteles (2007). Política, Carlos García Gual (trad.). Madrid: Espasa-Calpe.

Asís Garrote, D. de (1988). Formas de comunicación en la narrativa. Madrid: Editorial Fundamentos.

Beristáin, E. (2006). Diccionario de retórica y poética. México: Porrúa.

Beuchot, M. (2004). La querella de la conquista. Una polémica del siglo XVI. México: Siglo XXI.

Conesa, F. y Nubiola, J. (2002). Filosofia del lenguaje. Barcelona: Herder.

Cortés, H. (1988). Cartas de relación. México: Porrúa.

Díaz del Castillo, B. (2002). Historia verdadera de la conquista de la Nueva España. México: Editores Mexicanos Unidos.

Florescano, E. (2002). Memoria mexicana. México: Fondo de Cultura Económica.

Fuentes, C. (2007). Las dos orillas. En El naranjo. México: Punto de Lectura.

Gatlin, G. T. (2017). La identidad bicultural en Malinche y Las dos orillas. Revista CS, (23), 19-35. doi: https://doi .org/10.18046/recs.i23.2124

Heidegger, M. (1992). Arte y Poesía. Buenos Aires: Fondo de Cultura Económica.

Lafaye, J. (1988). Los conquistadores. México: Siglo XXI. 
León Portilla, M. (2003). Los antiguos mexicanos a través de sus crónicas y cantares. México: Fondo de Cultura Económica.

Masia, Á. (1971). Historiadores de Indias. Antillas y tierra firme. Barcelona: Bruguera.

Méndez, M. A. (1999). "Las dos orillas" del libro El naranjo de Carlos Fuentes. Lectura e intertextualidad. Gramma, (31), 82-87.

Olivier, F. (2007). Dos conquistas: paralelismo e inversión entre "Las dos orillas" y "Las dos Numancias" en El Naranjo de Carlos Fuentes. Actas del XV Congreso de la Asociación Internacional de Hispanistas, vol. IV. México: Fondo de Cultura Económica.

Pimentel, L. A. (2005). El relato en perspectiva. Estudio de teoria narrativa. México: Siglo XXI-UNAM.

Redondo Goicoechea, A. (1995). Manual de análisis de literatura narrativa. La polifonía textual. Madrid: Siglo XXI.

Ricard, R. (2005). La conquista espiritual de México. Ensayo sobre el apostolado y los métodos misioneros de las órdenes mendicantes en la Nueva España 1523-1524 a1572. México: Fondo de Cultura Económica.

Sahagún, B. de (1999). Historia general de las cosas de la Nueva España. México: Porrúa.

Todorov, T. (2003). La conquista de América. El problema del otro. México: Siglo XXI.

Zavala Alvarado, L. (2007). Manual de análisis narrativo. Literario, cinematografía, intertextual. México: Trillas.

\section{Notas}

1 Las fuentes de la conquista señalan que los españoles en un principio fueron considerados centauros o seres de dos cabezas y seis patas, también los confundieron con dioses, por lo cual les ofrecieron ofrendas y comida de acuerdo a su condición divina (Sahagún 1999).

2 Aristóteles en la Política consideró que había hombres que eran esclavos por naturaleza, esto es, estaban destinados al servicio de otros, pero también quienes eran señores y legítimos poseedores de sus bienes y tenían una condición diferente (2007, pp. 43-48).

3 Beristáin aclara que la cultura se define como un conjunto organizado de sistemas de comunicación de gran complejidad, de tal manera que "Todo aquello respecto a lo cual pensamos es cultura, pues no existe ningún aspecto de la vida humana que no esté relacionado con la cultura [...] porque la cultura se aprende, es siempre aprendida, y todo aprendizaje se realiza mediante el lenguaje, ya que cada individuo descubre el mundo a través de los nombres de las palabras [...]" (2006, p. 127).

4 El escritor mexicano Carlos Fuentes en el cuento retoma el tema de la conquista de México y reflexiona desde un personaje histórico como Jerónimo de Aguilar, quien fue partícipe en el hecho histórico tratado en Historia verdadera de la conquista de México, de Bernal Díaz. María Alejandra Méndez señala que Carlos Fuentes “[...] por momentos toma los hechos de la crónica y los hace suyos; por momentos, se aleja y presenta una perspectiva propia en la que inscribe su versión de la conquista. El relato comienza con la inclusión del yo 'narrador', testigo de los hechos. El autor emplea el recurso propio de la crónica, el personaje relata los acontecimientos en los que participó [...] Se exponen deseos, dudas, sentimientos simultáneamente con el relato de los acontecimientos. Así el 'yo narrador' surge desdoblado en personaje y narrador" (1999, p. 83).

5 En el libro doceno que trata de la conquista de México, incluido en la Historia general de las cosas de la Nueva España, se expresan una serie de presagios que anunciaban que el orden socio-político y religioso cambiaría y se avecinaba la caída del Imperio Azteca (Sahagún, 1999). 